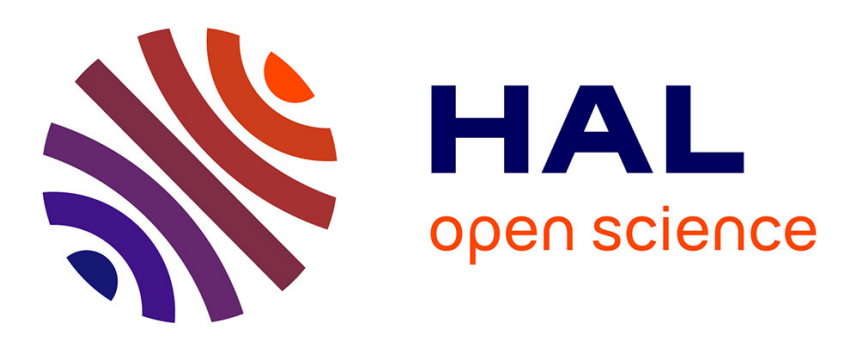

\title{
Nanoparticles deposit location control on porous particles during dry impregnation in a fluidized bed
}

Laurie Barthe, Karine Philippot, Bruno Chaudret, Nadine Le Bolay, Mehrdji

Hemati

\section{- To cite this version:}

Laurie Barthe, Karine Philippot, Bruno Chaudret, Nadine Le Bolay, Mehrdji Hemati. Nanoparticles deposit location control on porous particles during dry impregnation in a fluidized bed. Powder Technology, 2014, vol. 257, pp. 198-202. 10.1016/j.powtec.2014.02.040 . hal-01136567

\section{HAL Id: hal-01136567 https://hal.science/hal-01136567}

Submitted on 27 Mar 2015

HAL is a multi-disciplinary open access archive for the deposit and dissemination of scientific research documents, whether they are published or not. The documents may come from teaching and research institutions in France or abroad, or from public or private research centers.
L'archive ouverte pluridisciplinaire HAL, est destinée au dépôt et à la diffusion de documents scientifiques de niveau recherche, publiés ou non, émanant des établissements d'enseignement et de recherche français ou étrangers, des laboratoires publics ou privés. 


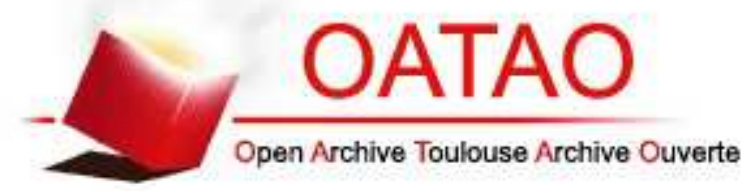

\section{Open Archive TOULOUSE Archive Ouverte (OATAO)}

OATAO is an open access repository that collects the work of Toulouse researchers and makes it freely available over the web where possible.

This is an author-deposited version published in : http://oatao.univ-toulouse.fr/ Eprints ID : 13762

To link to this article : doi: $10.1016 / \mathrm{j}$.powtec.2014.02.040 URL : http://dx.doi.org/10.1016/j.powtec.2014.02.040

To cite this version : Barthe, Laurie and Philippot, Karine and Chaudret, Bruno and Le Bolay, Nadine and Hemati, Mehrdji Nanoparticles deposit location control on porous particles during dry impregnation in a fluidized bed. (2014) Powder Technology, vol. 257. pp. 198-202. ISSN 0032-5910

Any correspondance concerning this service should be sent to the repository administrator: staff-oatao@ listes-diff.inp-toulouse.fr 


\title{
Nanoparticles deposit location control on porous particles during dry impregnation in a fluidized bed
}

\author{
Laurie Barthe ${ }^{\mathrm{a}}$, Karine Philippot ${ }^{\mathrm{b}}$, Bruno Chaudret ${ }^{\mathrm{b}}$, Nadine Le Bolay ${ }^{\mathrm{a}}$, Mehrdji Hemati ${ }^{\mathrm{a}, *}$ \\ a Université de Toulouse, Laboratoire de Génie Chimique, UMR CNRS 5503, INP-ENSIACET, 4, allée Emile Monso BP 84324, Toulouse Cedex 04, France \\ b Laboratoire de Chimie de Coordination, UPR CNRS 8241, 205 route de Narbonne, 31077 Toulouse Cedex 04, France
}

Keywords:

Metallic nanoparticles

Fluidized bed

Dry impregnation

Deposit location

Drying

\begin{abstract}
A B S T R A C T
This work deals with the synthesis of composite materials, catalytic or not, by an innovating technique named dry impregnation in a fluidized bed. This process permits the obtainment, in only one apparatus, of composite materials which, by the traditional way, must successively undergo the stages of impregnation, filtration, drying and calcination/activation. Its principle consists in the spraying of a solution containing a metallic precursor into a hot fluidized bed of porous particles as a chosen support. After the impregnation step, the decomposition of metallic precursor and metal activation can be operated in the same reactor. It is found that the competition between two phenomena (drying and capillary) controls the deposit location.

This paper presents experimental results obtained during the dry impregnation of coarse and fine porous particles using different types of precursors: inorganic precursors (metallic salts), metal organic complexes and a colloidal suspension containing preformed metallic nanoparticles (rhodium). The effect of drying parameters (solvent content in gas phase and temperature) on deposit distribution within the support grains at the local scale is examined.

It appeared that a fast drying leads to a deposit located only at the external particle surface (similar to a surface coating), whereas a uniform deposit on the whole particle volume is obtained with slow drying conditions. It indicates that dry impregnation in fluidized beds is very flexible and, by a simple modification of the operating conditions, we can fix the deposit location.
\end{abstract}

\section{Introduction}

Usually, the preparation method of composite materials such as supported catalysts consists in the immersion of the chosen support in a precursor solution under stirring to favour the diffusion inside the support grains. After this impregnation, the composite material successively undergoes the stages of filtration, drying and calcination/activation. This technique is easy to carry out but presents a weakness: the dependence of the deposit location on the physico-chemical properties of the solution-support couple. Indeed, a control of the deposit location represents a real challenge, particularly in catalysis [1,2]. Moreover, to obtain a high metal loading, these four steps should be repeated several times.

Supported catalyst synthesis can also be achieved using an innovating technique, namely dry impregnation in a fluidized bed [3]. This technique is a "one pot process". It consists in spraying a precursor solution into a hot fluidized bed of porous particles.

During operation, the pulverised solution penetrates inside the porous support by capillarity (liquid spreading/penetration), and at the same time the solvent is evaporated thanks to the energy brought by the fluidization gas (drying). These phenomena depend on:

\footnotetext{
* Corresponding author.

E-mail address: Mehrdji.Hemati@ensiacet.fr (M. Hemati).
}

- The process related variables (fluidization gas flow rate, bed temperature, atomizing gas and liquid flow rates, and atomizer location),

- The physicochemical properties (liquid interfacial tension, liquid viscosity, contact angle between solid and liquid, nature and texture of solid particles).

The interdependency between these two kinds of parameters determines the product quality and the metal repartition into the porous particles.

Few studies are reported on the dry impregnation technique. Previous works from our laboratory, concerning impregnation of porous particles with aqueous solutions of metallic salts, showed the feasibility of manufacturing catalysts by direct impregnation of porous support particles through the pulverization of metallic precursor solutions in a hot fluidized bed [4-7]. It was shown that, under the chosen operating conditions, the efficiency of the metal deposition is close to $100 \%$ and the metal loading is directly related to the operating time and the liquid flow rate and concentration. It was found that the competition between the drying rate, depending on the processrelated variables, and the capillary penetration rate, depending on the physicochemical-related variables, controls the deposit location. A quasi uniform deposit inside the support particles is observed for soft drying. The metal nanoparticle size is controlled by the pore 
mean diameter of the support as well as the calcination operating protocol.

In order to determine the importance of the solvent evaporation process compared to the solution penetration by capillarity, an impregnation module, $I M$, was defined. It is the ratio between the drying characteristic time $\left(t_{d r y}\right)$ and a capillary penetration time $\left(t_{c a p}\right)$.

- $t_{c a p}$, the necessary time for liquid penetration in the pores, can be estimated from the following equation taken from the model of the parallel capillary beam [8]:

$t_{c a p}=\frac{2 \mu x^{2}}{\gamma_{L V}(\cos \theta) \cdot r_{\text {pore }}}$

where $\mu$ is the liquid viscosity, $x$ the pore length equivalent to the radius particle multiplied by the tortuosity factor, $\gamma_{L V}$ the interfacial tension, $\theta$ the contact angle and $r_{\text {pore }}$ the pore radius.

- $t_{d r y}$ is the time necessary for a particle saturated by pure solvent to be transformed into a dry particle under defined fluidized bed conditions (temperature and humidity). The calculation of this characteristic time is based on the mass and energy balances on a single wet particle considering that the mass transfer is controlled by external resistance (gas phase). The model's equations described in previous works [3,9] lead to the following equation:

$t_{d r y}=\frac{d_{p} \chi \rho_{s}}{6 k_{y}\left(Y_{i}-Y^{-}\right)}$

where $d_{p}$ is the particle diameter, $\chi$ the internal support porosity, $\rho_{s}$ the solvent density, $k_{y}$ the overall mass transfer coefficient, $Y$ the average solvent content in the bed atmosphere determined by overall mass balance on the reactor, and $Y_{i}$ the absolute solvent content at the interface (depending on the particle temperature and humidity).

Moreover, another criterion depending on $Y^{-}$and bed temperature was considered: $\zeta$ s, the solvent vapour saturation rate value. It is defined as the ratio between gas solvent content in the bed and its value at saturation (saturation solvent content).

Different feasibility tests carried out in our laboratory at soft, intermediate and fast drying conditions have shown that:

- For high $\zeta s(0.8 \leq \zeta s \leq 1)$ and high $I M$, an undesirable phenomenon of partial or complete bed defluidization (wet quenching) is observed.

- For slow drying conditions $(0.2 \leq \zeta s \leq 0.8$ and IM greater than 10$)$, the metallic precursor deposit is located inside the porous matrix.

- For fast drying conditions ( $\zeta s<0.2$ and IM less than 10 ), the deposit is located on the support particle surface.

This study concerns the effect of drying parameters (solvent content in gas phase and temperature) on deposit distribution within the composite materials. The experiments are carried out using various types of precursors (metallic salts, metal organic precursor solutions and colloidal suspensions containing preformed metal nanoparticles) and various particle sizes (from $100 \mu \mathrm{m}$ to a few millimetres).

\section{Methods and materials}

\subsection{Supports and metal sources}

Two solids, different in their nature and grain size, were used as catalyst supports: fine porous silica particles and coarse activated $\gamma$ alumina particles. Their principal physical properties are reported in Table 1. Various types of precursors were sprayed on the supports.

Aqueous solutions of metallic salts were prepared by dissolution of inorganic salts in water. Two precursors were used: iron nitrate $\mathrm{Fe}\left(\mathrm{NO}_{3}\right)_{3} \cdot 9 \mathrm{H}_{2} \mathrm{O}$ and manganese nitrate $\mathrm{Mn}\left(\mathrm{NO}_{3}\right)_{2} \cdot 4 \mathrm{H}_{2} \mathrm{O}$. The
Table 1

Physical properties of the porous supports.

\begin{tabular}{lcc}
\hline Properties & Silica gel & Alumina \\
\hline Mean diameter $\mathrm{d} 50 d_{p}(\mu \mathrm{m})$ & 120 & 2400 \\
Specific surfaces $S_{\text {bet }}\left(\mathrm{m}^{2} / \mathrm{g}\right)$ & 530 & 330 \\
Pore volume $V_{p}\left(\mathrm{~cm}^{3} / \mathrm{g}\right)$ & 0.8 & 0.3 \\
Particle density $\rho\left(\mathrm{kg} / \mathrm{m}^{3}\right)$ & 910 & 2200 \\
Internal porosity $X(\%)$ & 60 & 43 \\
\hline
\end{tabular}

concentrations are indicated in Table 2 . These precursors are very water soluble. The saturation concentration at $20{ }^{\circ} \mathrm{C}$ is respectively $300 \mathrm{~g}$ of crystals/100 $\mathrm{g}$ of water and $322 \mathrm{~g}$ of crystals/100 $\mathrm{g}$ of water.

Metal organic precursor solutions were prepared with an organometallic complex as precursor such as $\left.\operatorname{PdCl}\left(\eta^{3}-\mathrm{C}_{3} \mathrm{H}_{5}\right)\right]_{2}$ (palladium allyl chloride). The most suitable solvent permitting the obtainment of a solution from the complex is tetrahydrofuran (THF). This solvent must be distilled and degassed before use to remove traces of peroxides, oxygen, and water to ensure the stability of the solution during the impregnation step.

Colloidal aqueous suspensions containing rhodium (0) colloids were prepared as previously described [10]. More precisely, sodium borohydride was added to an aqueous solution containing the surfactant HEA16Cl (N,N-dimethyl-N-cetyl-N-(2-hydroxyethyl)ammonium salts). This solution was quickly added under vigorous stirring to an aqueous solution of the precursor $\mathrm{RhCl}_{3} \cdot 3 \mathrm{H}_{2} \mathrm{O}$. The initial red solution darkened immediately attesting that an aqueous Rh0 colloidal suspension is obtained, which remains stable for a long time. The average rhodium particles size is around $2.4 \mathrm{~nm}$.

\subsection{Experimental set-up}

Depending on the metal source nature, the experiments were carried out under air or controlled atmosphere (inert or reductive) in a batch fluidized bed (Fig. 1). This reactor is a stainless steel cylindrical column with $0.1 \mathrm{~m}$ inner diameter and $0.5 \mathrm{~m}$ height, described by Barthe [7].

The gas distributor is a stainless steel perforated plate with a porosity of $0.5 \%$. The fluidizing gas flow rate is measured by means of a rotameter and preheated by an electrical heater before entering the bed. The elutriated particles and solvent vapours are collected at the column outlet respectively by a cyclone and a condenser.

The metallic precursor solution is drawn up by a volumetric pump from a reservoir to an internal mixing of two-fluid spray nozzle. The atomizing gas flow rate is controlled by a needle valve and measured by a rotameter. The bed temperature is controlled by means of a PID regulator. Monitoring of temperature and pressure drop takes place during operation.

The solid sampling system is achieved with a vacuum circuit. The sampling with a controlled atmosphere is done through a nitrogen circuit. In addition it enables working with oxygen and water sensitive products.

\subsection{Characterization methods}

The metal deposit location of the samples was studied using different techniques. The composite materials were analysed by an optical microscope and a Transmission Electron Microscope (TEM). In the case of TEM observations, the samples were cut by ultramicrotomy.

\subsection{Operating conditions}

The different operating conditions are listed in Table 2. The first six experiments were carried out with inorganic precursors. Organometallic complexes have been used in experiment S7 while a colloidal suspension was sprayed for experiments S8 and S9. For each precursor type various experiments were carried out with different values of IM 
Table 2

Experimental conditions.

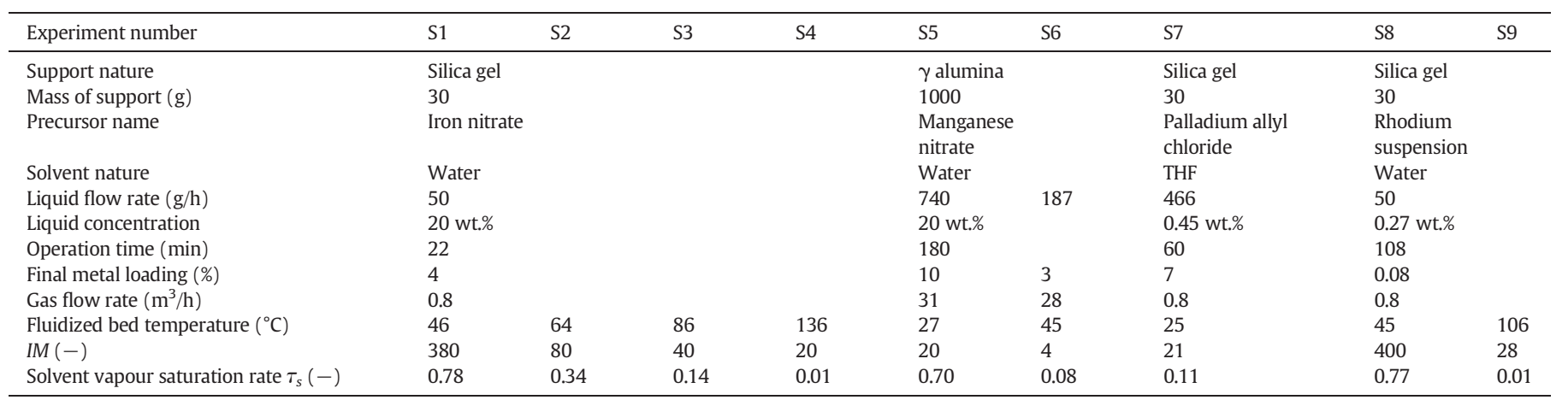

and $\zeta s$ corresponding to the three zones previously defined: unstable operation (partial or complete bed defluidization), soft drying and fast drying. The pure solvent used is water except for experiment S7 for which tetrahydrofuran (THF) was used since the corresponding precursor is water sensitive.

The operating condition choice to obtain various deposit location of the precursor in the support can be done very easily. The experiments should be carried out keeping the same solution and fluidization gas flow rate, modifying only the bed temperature. It is the case of experiments S1 to S4 (for iron deposit) and experiments S8 and S9 (for rhodium deposit). The evolutions of the characteristic times and the solvent content in bed atmosphere versus bed temperature are obtained using the model's equations described in previous works $[3,9]$. These theoretical results permit the determination of the influence of temperature on the characteristic parameters $\zeta$ s and IM (Fig. 2a and b). The graph can be divided into the three zones previously described: unstable (1), slow drying (2) and fast drying (3).

According to the operating conditions and to the values of $\zeta s$ and $I M$, the experiments $\mathrm{S} 1$ to $\mathrm{S} 4$ can be symbolized on the graph of Fig. 2a. It is possible to confirm the operation conditions and predict the deposit location through the choice of the bed temperature. The same can be done for experiments S8 and S9 (Fig. 2b).

\section{Results and discussion}

The deposit location of palladium-, iron- and manganese-composite materials was studied after an activation step leading to the formation of metallic nanoparticles. In the case of organometallic precursor (palladium) the activation step is operated under a nitrogen/ hydrogen mixture at $80{ }^{\circ} \mathrm{C}$ during $90 \mathrm{~min}$, while for inorganic precursors the samples are heated up in air to $450{ }^{\circ} \mathrm{C}$ (for iron) or to $300{ }^{\circ} \mathrm{C}$ (for manganese). Activation and calcination conditions were chosen to favour the formation of easily observable metallic nanoparticles clusters. These conditions were not optimized to obtain small individual nanoparticles [11]. In the case of rhodium composite materials, the deposit is already formed by metallic nanoparticles.

\subsection{Unstable conditions}

A few experiments were carried out in "unstable conditions" ( $\zeta s>0.8)$ in the case of iron nitrate spraying on fine porous silica particles. It was verified that these experiments could not be completed due to partial or complete bed defluidization (wet quenching).

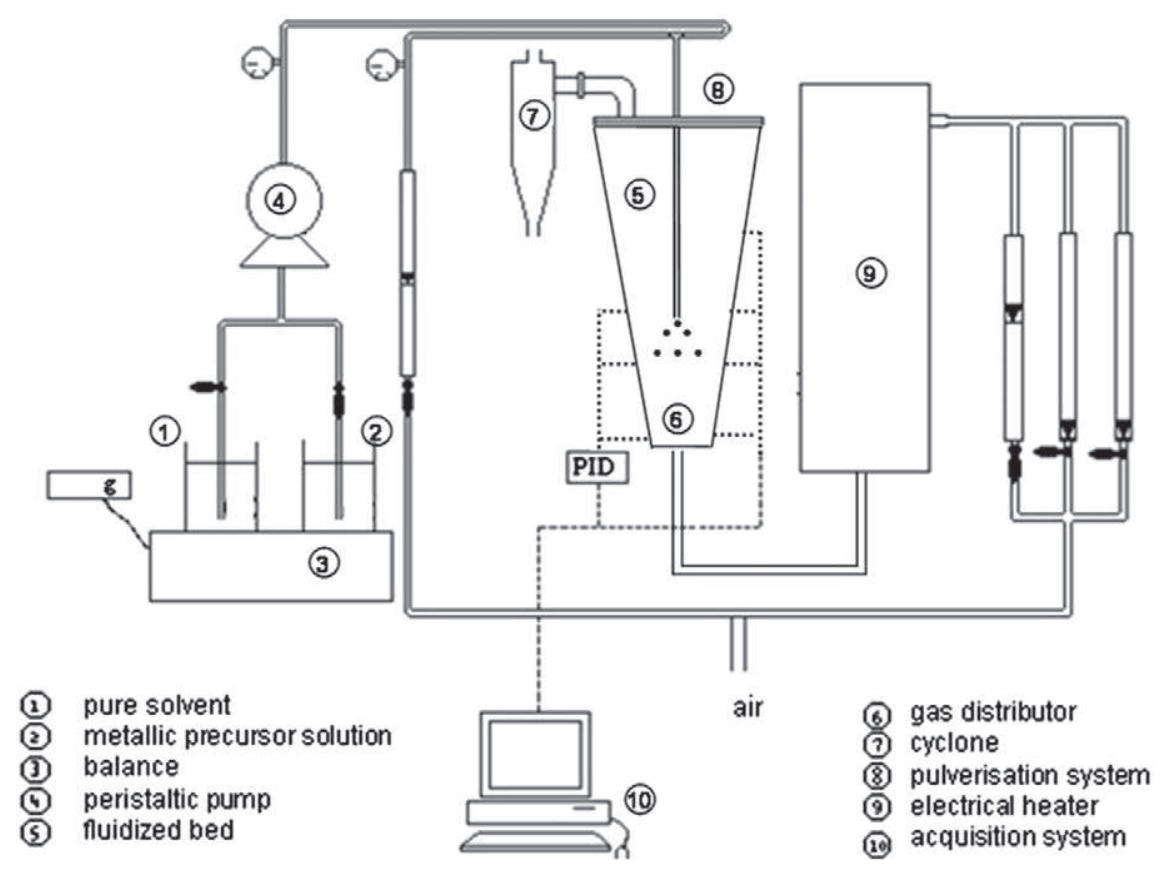

Fig. 1. Experimental set-up. 

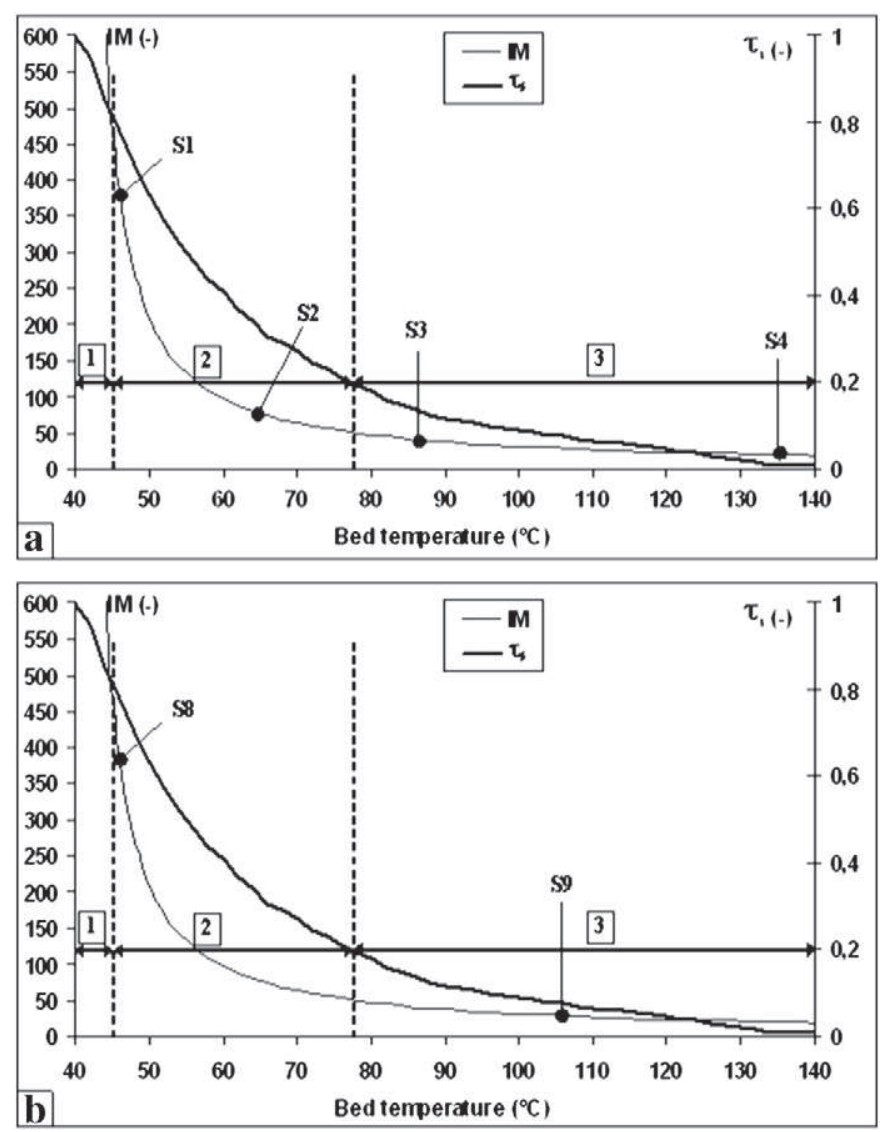

Fig. 2. IM and $\tau_{s}$ evolution with the bed temperature (a: iron deposit; b: rhodium deposit).

\subsection{Slow drying conditions}

Some of the experiments were carried out under operating conditions corresponding to slow drying $(0.2 \leq \zeta s \leq 0.8$ and high $I M)$ using inorganic precursors (S1, S2 and S5) and a colloidal suspension (S8).

The samples $\mathrm{S} 1$ and $\mathrm{S} 8$ were analysed by TEM (Fig. 3a and b).

The micrographs show that the deposit, characterized by the most darkened zones, is quasi uniform in the entire particle volume in the case of iron nanoparticles (a) and rhodium nanoparticles (b). In slow drying conditions, whatever the precursor nature, dry impregnation on fine porous particles leads to homogeneous deposit.

Thus, experiment S5 was carried out with coarse alumina particles to verify if this result, obtained with fine particles, is similar with bigger particles. Samples were prepared by spraying an inorganic precursor on coarse alumina particles. Three samples were removed from the fluidized bed at different operation times to characterize the evolution of the deposit distribution during the impregnation. They are numbered from S5.1 to S5.3, in ascending order of time residence in the bed and so of the metal deposit quantity. The cross section photographs are presented in Fig. 4.

These images show that the aqueous solution penetrates into the alumina particles. Moreover, the precursor deposit inside the solid is similar to the displacement of a front from the particle periphery towards its centre (S5.1 to S5.3). This internal position of the impregnation front is a function of the impregnation rate. For S5.1 and S5.2, the precursor is rather on the particle borders (egg shell catalysts). For $\mathrm{S} 5.3$, the precursor reaches the particle centre. The deposit is then uniform in the whole particle volume. Nearly constant concentration was detected on the section of the sample by Scanning Electron Microscopy coupled with Energy Dispersive X-ray. This phenomenon is comparable to a heterogeneous reaction between a gas and a porous solid when the
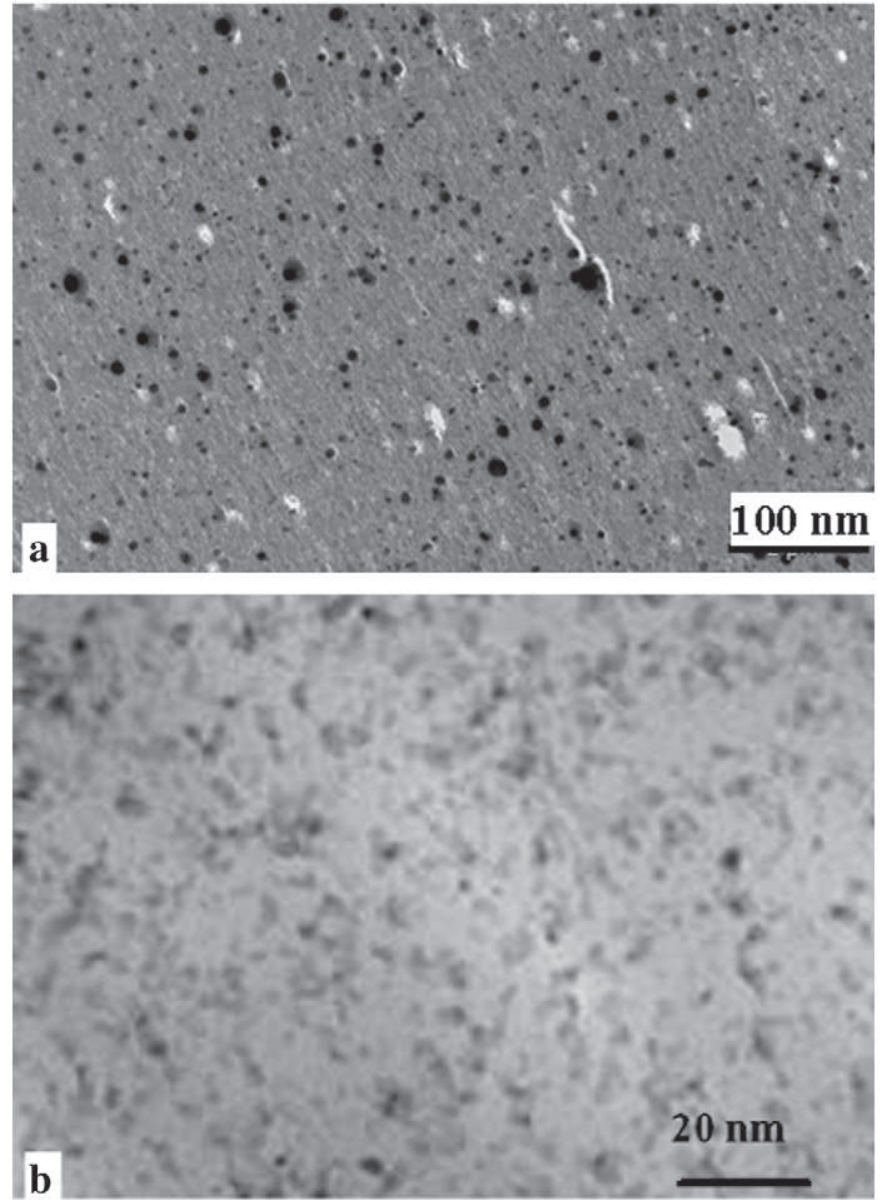

Fig. 3. TEM micrographs of various metallic nanoparticles on silica; a) iron (S1); b) rhodium (S8).

diffusion penetration time of the reactive gas is very high compared to the chemical reaction time. In this case, the reaction proceeds following a shrinking core model developed in a previous article [12].

\subsection{Fast drying conditions}

The other experiments were carried out under fast drying conditions ( $\zeta s<0.2$ and low IM) using inorganic precursors (S3, S4 and S6), an organometallic precursor (S7) and a colloidal suspension (S9).

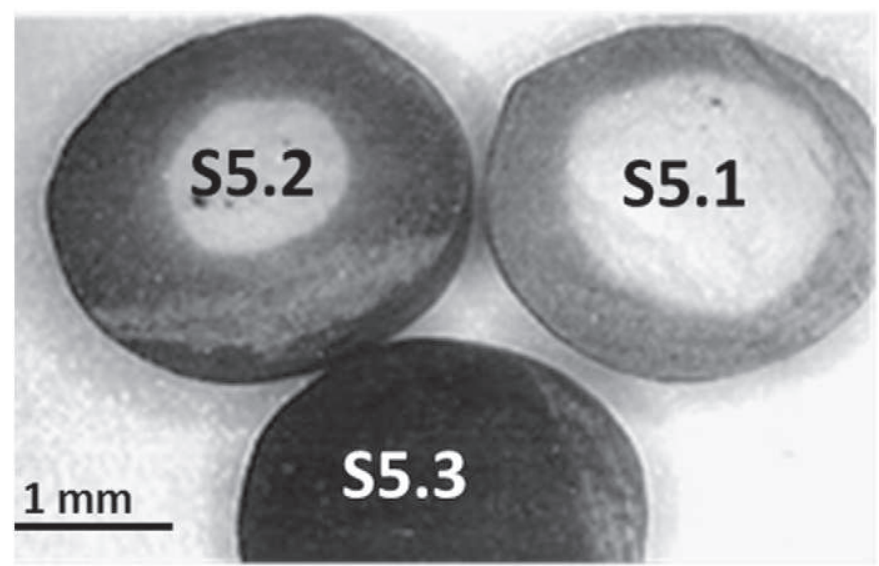

Fig. 4. Microscope micrographs of manganese deposit on alumina particles at different operating times (S5): S5.1 corresponds to $30 \mathrm{~min}, \mathrm{~S} 5.2$ to $90 \mathrm{~min}$ and S5.3 to $170 \mathrm{~min}$. 

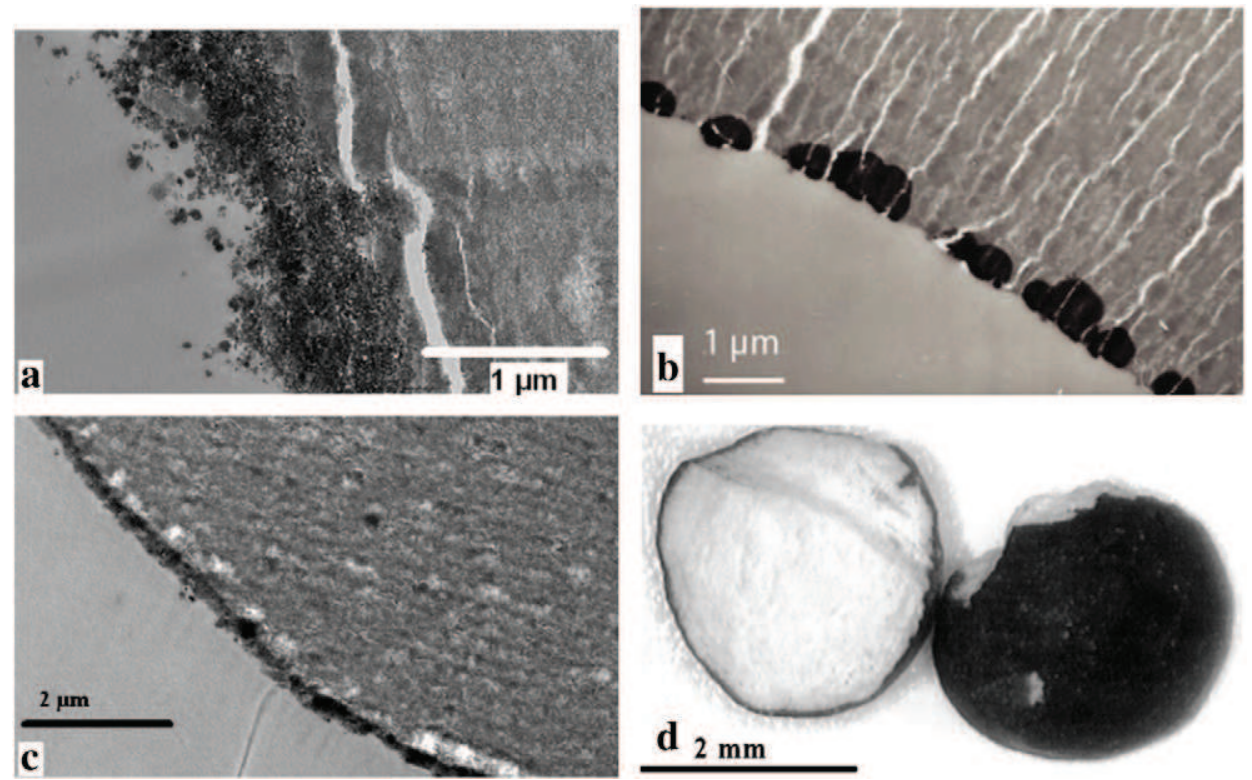

Fig. 5. EM or microscope micrographs for the various metallic nanoparticles; a) iron (S4); b) palladium (S7); c) rhodium (S9); d) manganese (S6).

Samples obtained for experiments S4, S7 and S9 were analysed by TEM (Fig. 5a, b and c). For each micrograph a deposit at the particle surface is observed, similar to a surface coating. The thickness of this coat can be controlled by the precursor quantity (and thus by the operation time) and is composed of individual nanoparticles into clusters. In fast drying conditions, whatever the precursor nature, the deposit is located at the silica particle surface.

To verify again that the conclusion obtained with fine particles can be extended to coarse particles, experiment $\mathrm{S} 6$ was carried out. S6 was analysed by microscopy. For fast drying conditions, micrographs of the external surface and the cross section of the samples presented in Fig. $5 \mathrm{~d}$ reveal that the deposit is located at the particle surface, with the intermediate and central zones remaining virgin.

\section{Conclusion}

In this paper, the synthesis of metal based-composite materials obtained by dry impregnation in a fluidized bed using different types of precursors is described. These precursors are inorganic precursors (metallic salts), metal organic complexes and a colloidal suspension containing preformed metallic nanoparticles (rhodium). The effect of operating parameters, solvent content in gas phase and bed temperature, on deposit distribution within the grains at the local scale is examined.

The results show that by correctly choosing operating conditions, the deposit location can be oriented. In addition, the impregnation of porous inorganic support by a colloidal suspension was also a success. A key operating parameter depending on the bed temperature and the solvent content in gas phase was defined: $\zeta$ s, the solvent vapour saturation rate. Three operation conditions are distinguished:

- Unstable operation (partial or complete bed defluidization), for high $\zeta s(0.8 \leq \zeta s \leq 1)$. In this zone a low increase of the liquid flow rate or a reduction of the gas inlet temperature can lead to wet quenching.

- "Soft drying conditions" are characterized by intermediate values of $\zeta s(0.2 \leq \zeta s \leq 0.8)$ and $I M$ greater than 10 . The solid precursor deposit takes place homogeneously inside the particles.
- "Fast drying conditions" are characterized by high bed temperatures and low solvent saturation rates $(\zeta s<0.2)$. The deposit is then located on the particle external surface (egg shell catalysts).

Moreover, all results show that the deposit location can be controlled during the dry impregnation process whatever the precursor nature (organic, inorganic or colloidal suspension) and for a large range of support particle sizes (from $100 \mu \mathrm{m}$ to a few millimetres).

\section{Acknowledgements}

The authors would like to thank A. Roucoux and A. DenicourtNowicki from Institut des sciences chimiques de Rennes, team "Organométalliques: Matériaux et Catalyse" for their collaboration in synthesis of rhodium colloidal suspension.

\section{References}

[1] J.W. Fulton, Selecting the catalyst configuration, Chem. Eng. 93 (1986) 97-101.

[2] A. Lekhal, B. Glasser, J.G. Khinast, Impact of drying on catalyst profile of supported impregnation catalysts, Chem. Eng. Sci. 56 (15) (2001) 4473-4487.

[3] L. Barthe, S. Desportes, M. Hemati, K. Philippot, B. Chaudret, Synthesis of supported catalysts by dry impregnation in fluidized bed, Chem. Eng. Res. Des. 85 (A6) (2007) 1-11.

[4] M. Hemati, D. Steinmetz, B. Chaudret, K. Philippot, Fabrication de catalyseur d'un nouveau type par imprégnation en lit fluidise, Brevet EPI-PCT/FR 02/01795, 2001.

[5] M. Hemati, R. Cherif, K. Saleh, V. Pont, Fluidized bed coating and granulation: influence of process-related variables and physicochemical properties on the growth kinetics, Powder Technol. 130 (2003) 18-34.

[6] S. Desportes, D. Steinmetz, M. Hemati, K. Philippot, B. Chaudret, Production of supported asymmetric catalysis in a fluidized bed, Powder Technol. 157 (2005) 12-19.

[7] L. Barthe, Synthèse et dépôt de nanoparticules métalliques dans un support poreux par imprégnation en voie sèche cdans un lit fluidisé: élaboration de catalyseurs supportés, (PhD thesis) INP, Toulouse, 2007.

[8] N.T. Burdine, Relative permeability calculations from pore size distribution data, Pet Trans. Am. Inst. Min. Eng. 198 (1953) 71-77.

[9] S. Desportes, Imprégnation en voie sèche en lit fluidisé: application à la synthèse de catalyseurs supportés, (PhD thesis) INP, Toulouse, 2005

10] J. Schulz, A. Roucoux, H. Patin, Chem. Eur. J. 6 (4) (2000) 618-624.

[11] L. Barthe, M. Hemati, K. Philippot, B. Chaudret, Dry impregnation in fluidized bed: drying and calcination effect on nanoparticles dispersion and location in a porous support, Chem. Eng. Res. Des. 86 (4) (2008) 349-358.

[12] L. Barthe, S. Desportes, D. Steinmetz, M. Hemati, Metallic salt deposition on porous particles by dry impregnation in fluidized bed: effect of drying conditions on metallic nanoparticles distribution, Chem. Eng. Res. Des. 87 (2009) 915-922. 